\title{
Variation of Mechanical Properties of Polypropylene Composites with the Additives Content: An Empirical Mathematical Modeling Study
}

\author{
M. Mostafizur Rahman*, Iftekhar Chowdhury, M. Mastabur Rahman \\ Department of Chemical Engineering and Polymer Science, Shahjalal University of Science and \\ Technology, Sylhet-3114, Bangladesh
}

Received 10 November 2020, accepted in revised form 19 January 2021

\begin{abstract}
Polypropylene (PP) composites were prepared by using additives $\mathrm{CaCO}_{3} /$ rice husk ash (RHA) as filler, low density polyethylene (LDPE) as modifier, and jute fiber as reinforcement. The effects of filler, modifier, and chemically treated and untreated jute fiber reinforcement on the mechanical properties of the PP composites were studied. The result shows that incorporation of RHA in the PP matrix improves the tensile properties up to 16 $\%$ which is almost similar to that of $\mathrm{CaCO}_{3}$ incorporated $\mathrm{PP}$ composite. This result clearly indicates the potential use of RHA as filler in \% LDPE, and $30 \mathrm{wt} \%$ jute fiber.
\end{abstract}

Keywords: Polypropylene; Composites, Rice husk ash; Jute fiber reinforcement; Mechanical properties; Additives optimization.

(C) 2021 JSR Publications. ISSN: 2070-0237 (Print); 2070-0245 (Online). All rights reserved.

doi: http://dx.doi.org/10.3329/jsr.v13i2.50231 J. Sci. Res. 13 (2), 611-621 (2021)

\section{Introduction}

Polypropylene (PP) is widely used in various applications including construction, automotive, packaging, and apparel industries etc. PP is getting attraction as advanced composite matrix due to its low cost and easy processable behavior. However, it has very low surface tension resulting in low tensile modulus, poor toughness, and adhesion properties that limits its application in many broad areas [1]. In a series of academic theses were made to improve the surface characteristics of polypropylene matrix by using different technology [2-7]. In some cases, filler, modifier, and reinforcement were used in the PP matrix to improve the mechanical properties [8,9].

Armağan et al. [1] reported the adhesion strength of polypropylene-fabrics composite using nonwoven laminated fabrics. Yallew et al. [8] investigated the effect of jute reinforcement on the sliding wear properties of jute reinforced polypropylene composite. It was found that incorporation of jute fiber into PP matrix increases the wear resistance properties of the PP composites. Chengwu [9] reported that toughness and mechanical properties of the polypropylene can be improved with modification of PP matrix with inorganic filler (calcium carbonate) and organic materials (polyethylene). It was found

\footnotetext{
*Corresponding author: mostafizur.cep@gmail.com
} 
that impact strength of the composite increased with increasing content of $\mathrm{CaCO}_{3}$ up to a certain level and then decreased. The mechanical properties showed a downward trend after the first rise up to $10 \mathrm{wt} \% \mathrm{CaCO}_{3}$ content, which was found as optimum in the PP matrix. Fuad et al. [10] reported feasibility of using rice husk ash in PP matrix. Strapasson et al. [11] reported that addition of LDPE in the PP matrix decreased the yield strength, modulus of elasticity, and elongation at break.

Effect of filler $\left(\mathrm{CaCO}_{3}\right)$, modifier (LDPE), and reinforcement (jute fiber) on the mechanical properties of the PP composite were studied in the different investigations previously [12], and optimum compositions of them were identified separately. But, if the filler, modifier, and reinforcement are blended together in the PP matrix, then optimum value of them will be shifted. Therefore, a requirement for a new approach is necessary.

A technical feasibility of utilization of waste material, rice husk ash (RHA) generated from rice processing station (rice mill) as filler in the PP matrix was studied herein. An experiment was designed and performed to investigate the effect of RHA, $\mathrm{CaCO}_{3}, \mathrm{LDPE}$, and short jute fiber on the mechanical properties (tensile strength, elongation at break and impact strength) of the PP composite, and attempts were made to optimize the additives contents. An experiment was designed in which all possible combinations of the factors at all levels involved in the experiment were used. It was based on a full factorial design with three categorical factors. The composition of filler, modifier and reinforcement were taken as independent variables and tensile strength as the response. In view to study the interaction among the factors a full $2^{3}$ factorial experiment approach was adopted. A regression equation was obtained also to analyze the tensile strength and the optimum additives content.

\section{Materials and Method}

\subsection{Materials}

Granular PP was collected from China (China Dawn Group Co., Ltd.) and used as matrix in the preparation of composite. The PP was characterized in the laboratory, and found density of $881.8 \mathrm{~kg} / \mathrm{m}^{3}$ and a melt flow index of $10.56 \mathrm{~g} / 10 \mathrm{~min}$ (measured at $220{ }^{\circ} \mathrm{C}$ and $2 \mathrm{~kg}$ load). $\mathrm{CaCO}_{3}$ was collected from China (Product of Xian Hannod Biotech Co., Ltd.). RHA was collected from local rice mill where it is generated as waste product. Collected RHA was heated at $840{ }^{\circ} \mathrm{C}$ in the furnace in view to complete combustion of sunburn carbon. Specific surface area of RHA was determined by Blaine surface area test following ASTM C 204-94 method. The specific surface area and the bulk density of RHA were found $5553 \mathrm{~cm}^{2} / \mathrm{g}$ and $0.33 \mathrm{~g} / \mathrm{cm}^{3}$ respectively. $\mathrm{SiO}_{2}$ content in the RHA was found $88 \%$ and Particle sizes of RHA were in the range of 75-425 $\mu \mathrm{m}$. Low density polyethylene (LDPE) in granular form and jute fiber were collected from local market. 


\subsection{Chemical treatment of jute fiber}

Extra pure $\mathrm{NaOH}(98-99 \%)$ pellet was used for the chemical treatment of jute fiber. Collected jute fiber was washed with distilled water, and immersed in $10 \%$ of $2.5 \mathrm{M}$ of $\mathrm{NaOH}$ solution at room temperature for $24 \mathrm{~h}$. Then the soaked jute fiber was washed with tap water and finally running distilled water for several times. After washing $\mathrm{pH}$ level of the wet fiber was measured. The jute fibers were dried firstly at atmosphere and finally at $80{ }^{\circ} \mathrm{C}$ in the oven.

Fiber-OH $+\mathrm{NaOH} \longrightarrow$ Fiber-O- $\mathrm{Na}^{+}+\mathrm{H}_{2} \mathrm{O}$

\subsection{Preparation of composites}

Dried jute fibers were cut into short fibers (1-3 mm length) and dried at $40{ }^{\circ} \mathrm{C}$ in an oven before using. PP composites containing 0-20 wt $\%$ RHA/CaCO $\mathrm{CO}_{3}, 0-10 \mathrm{wt} \% \mathrm{LDPE}$, and 0$40 \mathrm{wt} \%$ jute fibers were prepared at $170{ }^{\circ} \mathrm{C}$ using a double roller open mixer machine (Product of Dong Guang LiNa Machinery Industrial Co., LTD, China) for $10 \mathrm{~min}$ and cut into small sizes suitable for loading inside the barrel of the injection molding machine (Model: JY-200ST, China) at a temperature of $170{ }^{\circ} \mathrm{C}$ for preparing the specimens of desired shape for different tests. Following five types of composite specimens were prepared.

\begin{tabular}{|c|c|c|}
\hline S.I & Composite types & Compositions \\
\hline i. & $\begin{array}{l}\text { Chemically treated and untreated (raw) jute } \\
\text { fiber reinforced PP composite }\end{array}$ & PP and 0-30 wt $\%$ short jute fiber \\
\hline ii. & PP-CaCO ${ }_{3}$ composite & $\mathrm{PP}$ and $0-25 \mathrm{wt} \% \mathrm{CaCO}_{3}$ \\
\hline iii. & PP-RHA composite & PP and $0-25$ wt $\%$ RHA \\
\hline iv. & PP-LDPE composite & PP and $0-20 \mathrm{wt} \% \mathrm{LDPE}$ \\
\hline v. & $\begin{array}{l}\text { PP composite specimens containing various } \\
\text { compositions of RHA, LDPE, and treated } \\
\text { jute fiber. }\end{array}$ & $\begin{array}{l}\mathrm{PP}, 2-20 \mathrm{wt} \% \text { RHA, } 2-10 \mathrm{wt} \% \text { LDPE } \\
\text { and } 5-30 \mathrm{wt} \% \text { chemically treated } \\
\text { short jute fiber }\end{array}$ \\
\hline
\end{tabular}

\subsection{Characterization of composites}

Test specimens were evaluated following standard methods; tensile properties including tensile strength, percent elongation, and impact strength of the PP composites were determined using universal testing machine (Model: QT-6201S, China) following ASTM D 638. The surface morphology of the PP composites was investigated by using a highresolution Scanning Electron Microscope (SEM, JEOL M JSM6360) with suitable accelerating voltage. 


\section{Results and Discussion}

\subsection{Tensile properties}

The variation of tensile strength is plotted with the jute fiber contents (wt \%) in the PP matrix and presented in Fig. 1. The Fig. demonstrates that tensile strength increases with the addition of jute fiber up to $25 \mathrm{wt} \%$ and thereafter it tends to decrease with the further addition. The maximum tensile strength $\sim 32.5 \mathrm{MPa}$ and $\sim 27 \mathrm{MPa}$ were found with the 25 $\mathrm{wt} \%$ treated and untreated jute fiber, respectively. Addition of excessive amount of jute fiber ( $>25 \mathrm{wt} \%$ ) results insufficient PP matrix to impregnate fibers that leads to improper mixing and poor interfacial bonding. The improper mixing leads to agglomeration and poor interfacial bonding across the fiber-matrix interface [9]. Fig. 1 shows that treated jute fiber in PP composites exhibits higher tensile strength than that of untreated one. This result is justified as chemical treatment of jute fiber with $\mathrm{NaOH}$ improves fiber-matrix interfacial adhesion [13]. So, the treated jute fiber might be taken as reinforcement for further composites preparation in this experiment.

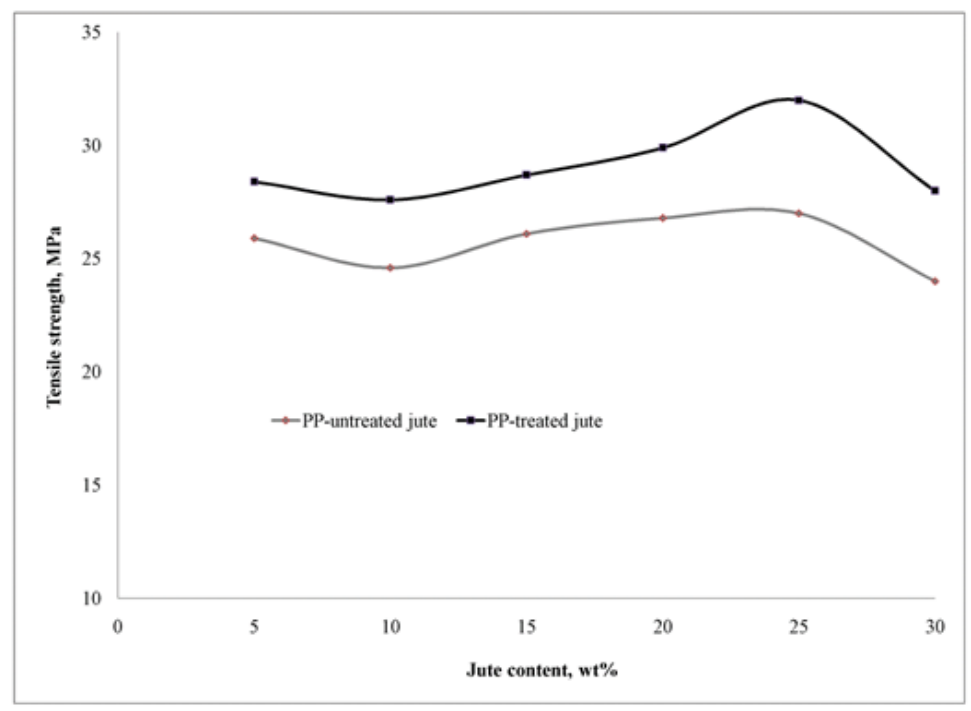

Fig. 1. Tensile strength as a function of jute fiber in the PP matrix.

The variation of tensile strength of PP composite with the amount (wt \%) of filler $\left(\mathrm{CaCO}_{3}, \mathrm{RHA}\right)$, modifier (LDPE), and reinforcement (treated jute fiber) in the composite is shown in Fig. 2. This Figure demonstrates that tensile strength of PP composite increases initially with the filler $\left(\mathrm{RHA}, \mathrm{CaCO}_{3}\right)$ content, and maximum tensile strength $\sim 22 \mathrm{MPa}$ and $\sim 21 \mathrm{MPa}$ are found at $10 \mathrm{wt} \%$ of both fillers $\mathrm{CaCO}_{3}$ and RHA, respectively. It shows that the tensile strength decreases with further increase in filler content. The initial increase in strength of the composite indicates good filler-matrix interactions, as a result more energy has been absorbed for the better filler-matrix interactions during the 
loading. The addition of filler can improve the interactions between the phases when subjected to external load and filler matrix induce shear yielding deformation that results absorption of more impact energy [9]. But incorporation of excessive amount of filler more than the optimum amount causes formation of voids and crack that results decrease in the mechanical properties of the composite. Utilization of waste material, RHA can be used as effective filler instead of $\mathrm{CaCO}_{3}$ in the PP matrix. Tensile strength versus LDPE content (wt \%) in the PP matrix curve is presented in Fig. 2 also. It demonstrates that tensile strength slightly declines with the addition of LDPE in the polypropylene matrix. The variation of tensile strength with jute fiber content is also shown in Fig. 2, which has been explained clearly in the previous section (Fig. 1).

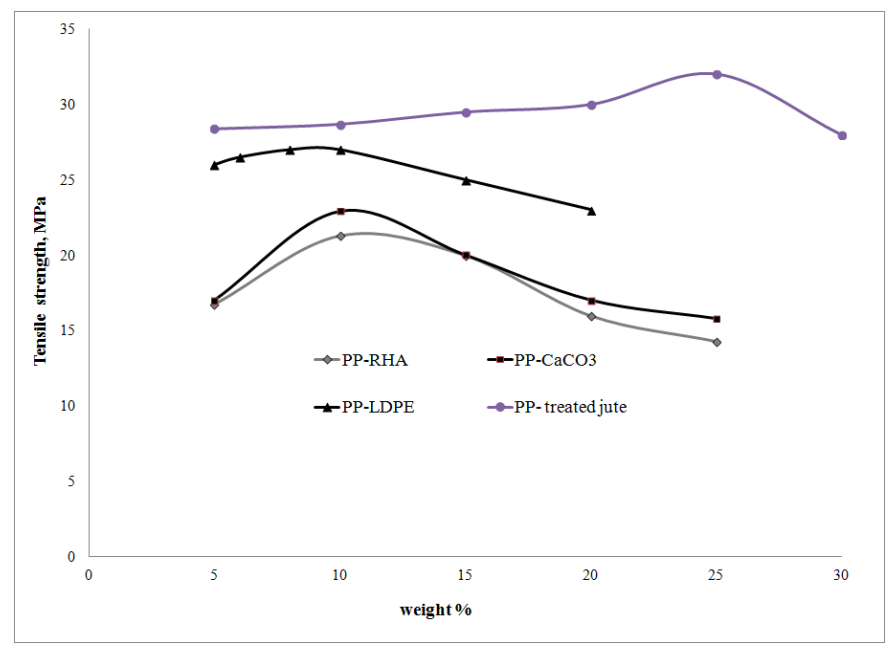

Fig. 2. Tensile strength as a function of filler, modifier and reinforcement in the PP matrix.

The elongation at break $\left(\mathrm{E}_{\mathrm{b}}\right)$ of the PP-CaCO 3 and PP-RHA composites is shown in Fig. 3. This Figure shows that $\mathrm{E}_{\mathrm{b}}$ increases up to $14 \%$ at $5 \mathrm{wt} \%$ filler $\left(\mathrm{RHA} / \mathrm{CaCO}_{3}\right)$ content. Further increment in filler $\left(\mathrm{RHA} / \mathrm{CaCO}_{3}\right)$ content results reduction in $\mathrm{E}_{\mathrm{b}}$. The reason is that excess filler (>5 wt \%) aggregates together by strong forces, which debond easily from the matrix and results reduction in mechanical properties. Further increment in filler content hinders aggregates formation and the elongation is decreased [9]. The elongation at break $\left(E_{b}\right)$ for PP-LDPE and PP-jute fiber composites are also shown in Fig. 3. From this figure it reveals that LDPE and Jute fiber content in PP composites show no significant effects on the elongation at break. 


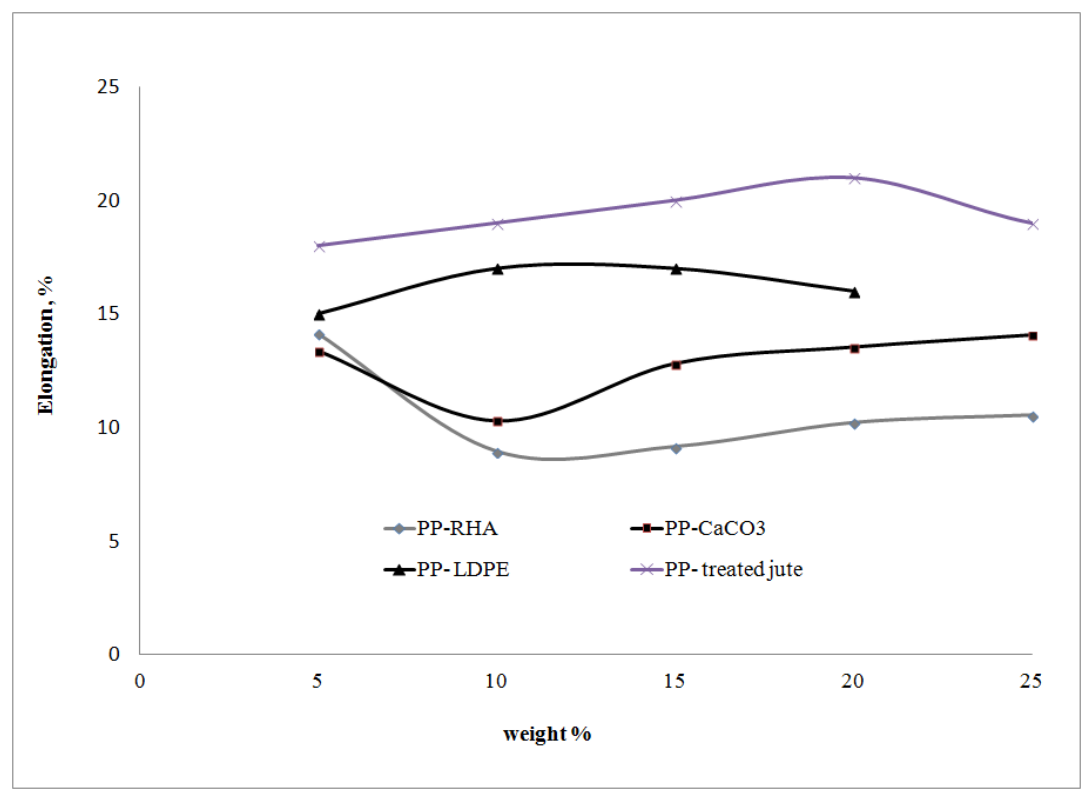

Fig. 3. Elongation as a function of filler, modifier and reinforcement in the PP matrix.

\subsection{Impact strength}

Similar to the tensile strength, addition of fillers $\left(\mathrm{CaCO}_{3} / \mathrm{RHA}\right)$ increases impact strength of PP composite. The variation of impact strength with the fillers is shown in Fig. 4. It is found that PP composite containing $8 \mathrm{wt} \%$ of $\mathrm{CaCO}_{3}$ and RHA exhibit maximum impact strength of $\sim 1.2$ and $\sim 1.0 \mathrm{~J}$, respectively. Further increment of filler content (>8 wt $\%$ ) reduces the impact strength. This is due to the fact that fillers used in this experiment more than the appropriate proportion causes uneven and discontinuous filler-matrix interaction in the composites and results reduction in impact strength [9]. On the other hand, in case of PP-treated jute fiber composite, the impact strength increases with increasing the jute fiber content upto $\sim 15 \%$ and then decreases. This may be due to the disproportionate mixing of matrix-reinforcement that causes the decrease of impact strength beyond this limit ( $15 \%$ jute fiber). Impact strength of the PP-LDPE composites somewhat decreases with increasing the LDPE content (Fig. 4).

\subsection{Experimental design and optimization of additives contents for the PP composites}

A full factorial design experiment is an empirical modeling technique to relate a set of controlled experimental factors and findings. In a full factorial design, all possible combinations of the factors at all levels involved in the experiment are used.

In this experiment, weight percentage (wt\%) of RHA, LDPE, and treated jute fiber in the PP composite were considered as independent variables and tensile strength as the 
response. The variables, wt $\%$ of three factors; RHA, LDPE, and treated jute fiber are designated as $\mathrm{X}_{1}, \mathrm{X}_{2}$ and $\mathrm{X}_{3}$ respectively. The low, middle, and high levels of each variable were designated as $-1,0$, and +1 respectively and depicted in Table 1 .

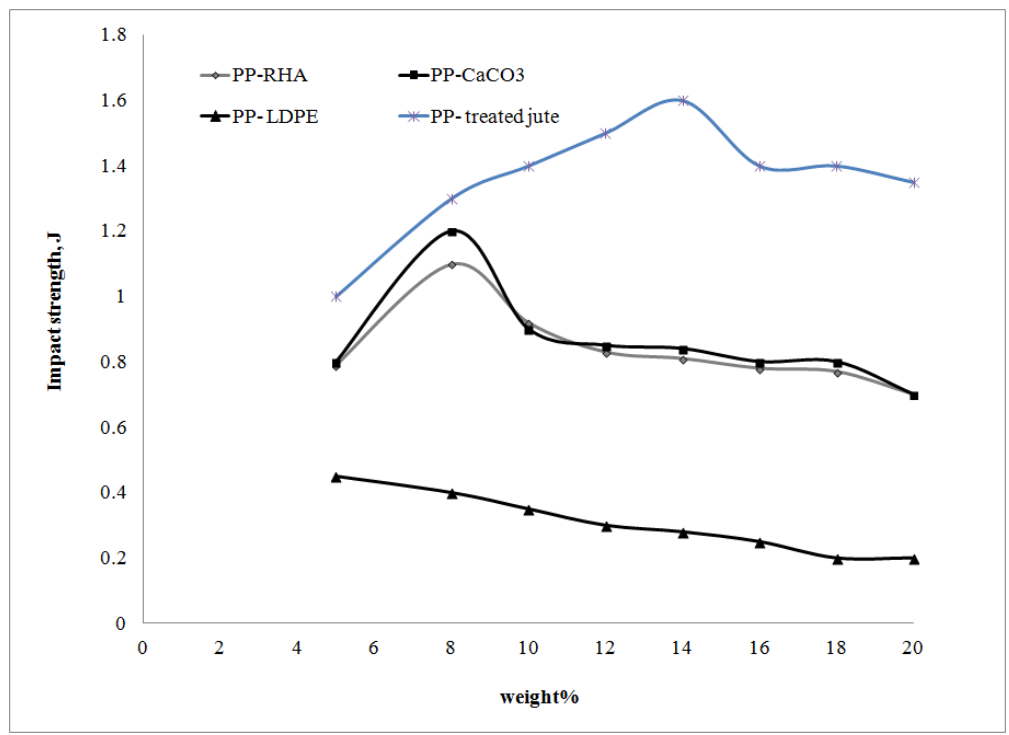

Fig. 4. Impact strength as a function of filler, modifier and reinforcement in the PP matrix.

Table 1. Levels and codes of independent variables for the full factorial design.

\begin{tabular}{lccccc}
\hline \multirow{2}{*}{ Independent variables } & \multicolumn{2}{c}{ Symbol } & \multicolumn{3}{c}{ Coded level } \\
\cline { 2 - 6 } & Coded & Uncoded & -1 & 0 & +1 \\
\hline RHA (wt\%) & $\mathrm{X}_{1}$ & $\mathrm{Z}_{1}$ & 0.02 & 0.11 & 0.2 \\
LDPE (wt\%) & $\mathrm{X}_{2}$ & $\mathrm{Z}_{2}$ & 0.02 & 0.06 & 0.1 \\
Treated jute fiber (wt\%) & $\mathrm{X}_{3}$ & $\mathrm{Z}_{3}$ & 0.05 & 0.18 & 0.3 \\
\hline
\end{tabular}

There are three experiments or factors and each factor is fixed at two levels. Thus, this is a two level three factor experiment. Thus, the number of experiments should be $\mathrm{N}=2^{3}=8$.

Table 2. A $2^{3}$ full factorial design with actual factors for the tensile strength of the PP composites.

\begin{tabular}{llcccccc}
\hline $\begin{array}{l}\text { Run } \\
\text { No. }\end{array}$ & \multicolumn{2}{l}{ Factors on natural scale } & \multicolumn{2}{c}{ Coded value } & & $\begin{array}{c}\text { Average tensile } \\
\text { strength, MPa }\end{array}$ \\
\hline & Z1 & Z2 & Z3 & X1 & X2 & X3 & $\hat{Y}$ \\
1 & 0.2 & 0.1 & 0.3 & +1 & +1 & +1 & 25.9 \\
2 & 0.2 & 0.1 & 0.05 & +1 & +1 & -1 & 24.1 \\
3 & 0.2 & 0.02 & 0.3 & +1 & -1 & +1 & 26.7 \\
4 & 0.2 & 0.02 & 0.05 & +1 & -1 & -1 & 28.6
\end{tabular}




\begin{tabular}{llcccccc}
\hline $\begin{array}{l}\text { Run } \\
\text { No. }\end{array}$ & \multicolumn{2}{l}{ Factors on natural scale } & Coded value & & $\begin{array}{c}\text { Average tensile } \\
\text { strength, MPa }\end{array}$ \\
\hline 5 & 0.02 & 0.1 & 0.3 & -1 & +1 & +1 & 25.8 \\
6 & 0.02 & 0.1 & 0.05 & -1 & +1 & -1 & 27.7 \\
7 & 0.02 & 0.02 & 0.3 & -1 & -1 & +1 & 30.4 \\
8 & 0.02 & 0.02 & 0.05 & -1 & -1 & -1 & 28.4 \\
\hline
\end{tabular}

A system with three significant independent variables $\mathrm{X}_{1}, \mathrm{X}_{2}$, and $\mathrm{X}_{3}$, the mathematical relationship of the variables can be approximated by the following quadratic regression equation (1):

$\mathrm{Y}=\mathrm{b}_{0}+\mathrm{b}_{1} \mathrm{x}_{1}+\mathrm{b}_{2} \mathrm{x}_{2}+\mathrm{b}_{3} \mathrm{x}_{3}+\mathrm{b}_{12} \mathrm{x}_{1} \mathrm{x}_{2}+\mathrm{b}_{13} \mathrm{x}_{1} \mathrm{x}_{3}+\mathrm{b}_{23} \mathrm{x}_{2} \mathrm{x}_{3}+\mathrm{b}_{123} \mathrm{x}_{1} \mathrm{x}_{2} \mathrm{x}_{3}$

The coefficients of regression equation are given by, $\mathrm{b}_{\mathrm{ji}}=\frac{\sum_{i=1}^{N} X_{j i} Y_{i a v g}}{\mathrm{~N}}$

The significant coefficients of the regression equation (1) $b_{0}, b_{1}, b_{2}, b_{3}, b_{12}, b_{13}, b_{23}$ and $b_{123}$ are $27.186,-0.886,-1.321,-0.128,0.493,0.527,0.574$ and 0.964 , respectively.

The final regression equation is,

$\mathrm{Y}=27.186-0.886 \mathrm{x}_{1}-1.321 \mathrm{x}_{2}+0.964 \mathrm{x}_{1} \mathrm{x}_{2} \mathrm{x}_{3}$

Fisher's test is done and found that this model is adequate to fit to the experiment. Eq. (3) is an empirical relation based on three process parameters namely $\mathrm{x}_{1}, \mathrm{x}_{2}, \mathrm{x}_{3}$ which is the $\mathrm{wt} \%$ of RHA, LDPE, and treated jute fiber content in the PP composite, respectively. The relation incorporates coded values of all these parameters ranging from -1 to +1 . From the Table 2, the optimum additives contents for the PP composite are found $2 \mathrm{wt} \%$ RHA, 2 $\mathrm{wt} \% \mathrm{LDPE}$, and $30 \mathrm{wt} \%$ jute fiber in the PP matrix. Tensile strength of the PP composite can be calculated analytically using the regression equation for any content of RHA, LDPE, and treated jute finer contents in the composite. This equation can be used to predict the composite performance based on its mechanical properties.

Mechanical properties of the PP composite prepared with optimum contents of additives ( 2 wt $\%$ RHA, 2 wt $\%$ LDPE, and $30 \mathrm{wt} \%$ jute fiber) were not shown in the separate graphs for the sake of brevity, and only the values of these properties in these compositions are presented in Fig. 5. Here it is also mentionable that when only filler $\left(\mathrm{CaCO}_{3} / \mathrm{RHA}\right)$ was used in PP matrix, the optimum content of filler in PP matrix was 10 wt\% and corresponding tensile strength was found $22 \mathrm{MPa}$ (Fig. 2). While, the incorporation of all the additives (filler, modifier, and jute fiber reinforcement together) in the PP matrix, the optimum content and corresponding tensile properties have been shifted significantly. This is because of synergistic effects of the additives in the PP matrix. 


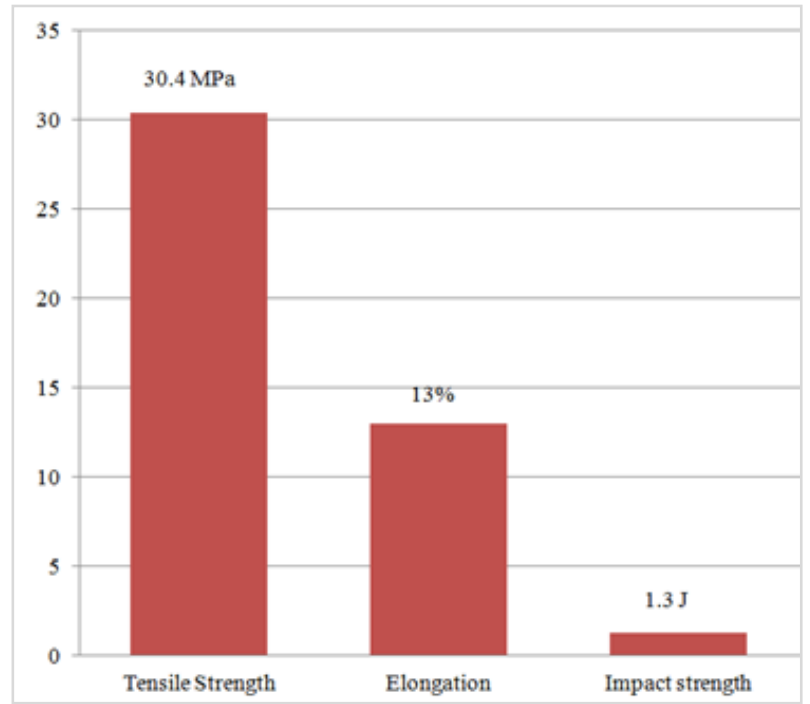

Fig. 5. Mechanical properties of PP composite containing optimum content of additives ( $2 \mathrm{wt} \%$ RHA, 2 wt $\%$ LDPE, and $30 \mathrm{wt} \%$ jute fiber).

\subsection{Surface morphology}

The morphology of virgin PP matrix and prepared PP composite with optimum content of additives ( 2 wt $\%$ RHA, 2 wt $\%$ LDPE, and $30 \mathrm{wt} \%$ jute fiber) was studied by SEM, and the images are presented in Fig 6(a, b). Fig. 6(a) demonstrates the microstructure of pure PP matrix and Fig. 6(b) illustrates the surface morphology of jute fiber reinforced PP composite containing filler and modifier. The microstructure of unreinforced pure PP matrix shows smooth surface, while, surface of jute fiber reinforced PP shows uneven and irregular, which clearly indicates fiber-matrix interactions. Similar to this study, it is found from the literature that incorporation of jute fiber to the PP matrix makes its surface rough and non-uniformity [14].

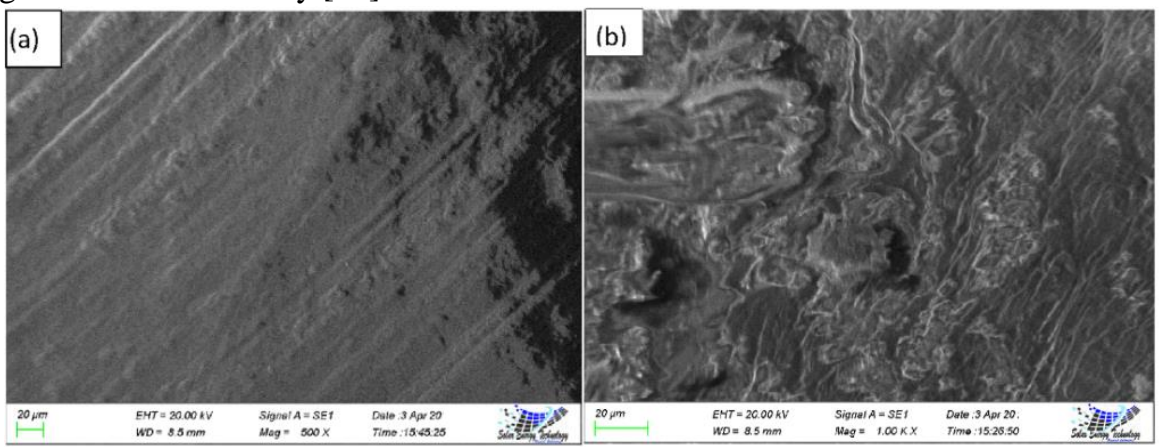

Fig. 6. SEM images, a) pure PP matrix, b) PP composite with filler, modifier, and reinforcement. 


\section{Conclusion}

PP with various compositions of filler $\left(\mathrm{CaCO}_{3} / \mathrm{RHA}\right)$, modifier (LDPE), and jute fiber reinforcement were used to prepare PP composites and characterized. The roles of filler, modifier, and reinforcement on the mechanical properties of the PP composites were determined. The filler, modifier, and reinforcement in the PP composites were optimized in this study separately. Chemically treated jute fiber reinforced PP composite shows higher tensile strength than that of untreated one and incorporation of $25 \mathrm{wt} \%$ jute fiber shows maximum tensile strength of $\sim 32 \mathrm{MPa} . \mathrm{CaCO}_{3}$ and RHA were used separately as filler, and their effects were studied. The result shows that incorporation of $10 \mathrm{wt} \%$ $\mathrm{CaCO}_{3}$ or $10 \mathrm{wt} \%$ RHA in the PP matrix provides maximum tensile strength of $\sim 22 \mathrm{MPa}$ and $\sim 21 \mathrm{MPa}$, respectively. It clearly indicates that the waste material, rice husk ash (RHA) generated from rice processing station (rice mill) can be considered to utilize as an alternative to conventional filler in the PP matrix. It was found that addition of $5 \mathrm{wt} \%$ $\mathrm{CaCO}_{3}$ or RHA provided maximum elongation at break $\left(\mathrm{E}_{\mathrm{b}}\right)$. PP composite with $8 \mathrm{wt} \%$ $\mathrm{CaCO}_{3}$ or RHA exhibits maximum impact strength (IS) of $\sim 1.2 \mathrm{~J}$ and $\sim 1 \mathrm{~J}$, respectively. A regression equation based on full factorial experiment design was developed and it was found that the optimum additives contents were $2 \mathrm{wt} \%$ RHA, $2 \mathrm{wt} \%$ LDPE, and $30 \mathrm{wt} \%$ jute fiber reinforcement in the PP matrix. Morphological properties were studied to understand the micro structure in view and to justify the mechanical properties as well. The uses of filler, modifier, and jute fiber reinforcement together in the PP composites can be a new arena of research to achieve their desired mechanical properties for various application fields.

\section{Acknowledgment}

The authors are thankful to the SUST research center for research grant 2016-17.

\section{References}

1. O. G. Armağan, B. K. Kayaoğlu, H. C. Karakaş, and F. S. Güner, Fibres Textiles in Eastern Europe 3, 96 (2013).

2. S. Shibata, Y. Cao, and I. Fukumoto, Compos. Part A- Appl. Sci. 39, 640 (2008). https://doi.org/10.1016/j.compositesa.2007.10.021

3. K. Oksman, M. Skrifvars, and J. F. Selin, Compos. Sci. Technol. 63, 1317 (2003). https://doi.org/10.1016/S0266-3538(03)00103-9

4. A. Arbeliaz, B. Fernandez, A. Valea, and I. Mondragon, Carbohydr. Polym. 64, 224 (2006). https://doi.org/10.1016/j.carbpol.2005.11.030

5. M. Avella, G. Bogoeva, A. Buzoarovska, M. E. Errico, G. Gentile, and A. Grozdanov, J. Appl. Polym. Sci. 104, 3192 (2007). https://doi.org/10.1002/app.26057

6. P. A. Sreekumar, K. Joseph, G. Unnikrishnan, and S. Thomas, Polym. Compos. 32, 131 (2011). https://doi.org/10.1002/pc. 21028

7. M. A. Sawpan, K. L. Pickering, and A. Fernyhough, Compos. Part A- Appl. Sci. 42, 888 (2011). https://doi.org/10.1016/j.compositesa.2011.03.008

8. T. B. Yallew, P. Kumar, and I. Singh, Procedia. Eng. 97, 402 (2014). https://doi.org/10.1016/j.proeng.2014.12.264 
9. C. Li, J. Chem. Pharm. Res. 6, 1467 (2014).

10. M. Y. A. Fuad, Z. Ismail, M. S. Mansor, Z. A. M. Ishak, and A. K. M. Omar, Polym. J. 27, 1002 (1995). https://doi.org/10.1295/polymj.27.1002

11. R. Strapasson, S. C. Amico, M. F. R. Pereira, and T. H. D. Sydenstricker, Polym. Test. 24, 468 (2005). https://doi.org/10.1016/j.polymertesting.2005.01.001

12. I. H. Chowdhury, M. M. Rahman, M. T. Uddin, and M. M. Rahman, J. Phys.: Conf. Series 1086, ID 012003 (2018). https://doi.org/10.1088/1742-6596/1086/1/012003

13. K. F. A. Dilfi, A. Balan, H. Bin, G. Xian, and S. Thomas, Polym. Compos. 39, E2519 (2018). https://doi.org/10.1002/pc. 24817

14. K. Begum and M. A. Islam, J. Sci. Res. 11, 89 (2019). https://doi.org/10.3329/jsr.v11i1.36450 